\title{
Diaporthe species associated with peach tree dieback in Hubei, China
}

\section{Dissanayake AJ ${ }^{1,2,4}$, *, Zhang $W^{1,4}$, *, Liu $M^{1}$, Hyde $\mathrm{KD}^{2}$, Zhao $\mathrm{WS}^{3}$, Li XH ${ }^{1,4}$, Yan JY1,4}

\author{
${ }^{1}$ Institute of Plant and Environment Protection, Beijing Academy of Agriculture and Forestry Sciences, Beijing 100097, \\ People's Republic of China \\ ${ }^{2}$ Center of Excellence in Fungal Research, Mae Fah Luang University, Chiang Rai 57100, Thailand \\ ${ }^{3}$ Department of Plant Pathology, China Agricultural University, Beijing 100093, People's Republic of China \\ ${ }^{4}$ Beijing Municipal Key Laboratory for Environmental Friendly Management on Pests of North China Fruits *These \\ authors contributed equally
}

Dissanayake AJ, Zhang W, Liu M, Hyde KD, Zhao W, Li XH, Yan JY 2017 - Diaporthe species associated with peach tree dieback in Hubei, China. Mycosphere 8(5), 533-549, Doi 10.5943/mycosphere/8/5/2

\begin{abstract}
Peach tree diseases have a variety of symptoms and causes. Only Botryosphaeriaceae taxa have been reported in association with peach trees in Chinese peach orchards. This study aims to identify and characterize Diaporthe species associated with peach trees in Jinshui Experimental Orchard in Hubei Academy of Agriculture Sciences, Hubei Province, China. The fungi were isolated from diseased peach trunks and shoots showing exudates. Fungal identification was accomplished using a combination of morphological and pathogenic characteristics together with phylogenetic analyses based on internal transcribed spacer (ITS), partial translation elongation factor 1- $\alpha$ (EF1- $\alpha), \beta$-tubulin (BT) and calmodulin (CAL) sequences. A total of 48 Diaporthe isolates were obtained from 62 diseased samples and most isolates were identified as Diaporthe eres $(69 \%)$, followed by D. momicola sp. nov (12.5\%), D. pescicola sp. nov. (10\%) and D. taoicola sp. nov. (8.5\%). All identified species were able to cause necrotic lesions at different levels of severity when inoculated into detached peach shoots
\end{abstract}

Key words - Diaporthaceae - Morphology - Multi-gene phylogeny - Pathogenicity - Prunus persica Taxonomy

\section{Introduction}

Although the botanical term for peach, Prunus persica L., refers to Persia (presently Iran), this fruit was first domesticated and cultivated in north western China (Faust \& Timon 2010). Peaches have been cultivated in China since approximately 2000 BC (Geissler 2009, Singh et al. 2007) and have been mentioned in Chinese writings as far back as the 10th century BC. According to FAOSTAT (Food and Agricultural Organization 2013-United Nations), China is the top peachproducing country, with a production of 11.9 million tons in 2013, which accounted for $50 \%$ of the global production.

Peach tree vigor and yield can be affected by many biotic and abiotic factors, including numerous fungal pathogens that affect the quality and quantity of the harvested fruit (Chen et al. 2015). Wood-decay fungi have been reported on peach (Adaskaveg \& Ogawa 1990, Adaskaveg et al. 1993, Petersen 1960, 1961); these fungi grow on limbs and trunks of different ages and/or health status. Taxa of the genus Monilinia Hon. and in some cases, Fusicoccum-like pathogens, are thought to be primarily responsible for shoot blight in peach trees (Thomidis \& Michailides 2009). Some pathogens are directly associated with peach tree decline and death (e.g., Armillaria staud.), while the role of other fungal species such as Trametes 
Fr., Ganoderma P. Karst., and Stereum Hill ex Pers. remains unclear (Chen et al. 2015). Various fungi have been reported to grow in wounds on peach trees caused by pruning and other orchard operations (Adaskaveg et al. 1993, Doepel et al. 1979). Shoot blight has become an increasing problem in peach-producing areas worldwide, with serious economic significance (Lalancette et al. 2003).

Peach production in Hubei Province in China currently covers more than 46,000 ha and is an important agricultural commodity in the province, producing an annual crop valued in excess of US \$134 million (Wang et al. 2011). A severe decline of peach trees due to botryosphaeriaceous pathogens has occurred in Hubei Province, one of the most important peach-production areas of China (Wang et al. 2011). Botryosphaeriaceous taxa are reported to cause fungal gummosis on the trunk and branches of peach trees and pose an increasing risk to the peach industry in Hubei Province (Wang et al. 2011). Although Diaporthe Nitschke has been reported to cause diseases of peach trees in many countries (Farr et al. 1999, Lalancette \& Robison 2001, Lalancette et al. 2003, Thomidis \& Michailides 2009, Uddin et al. 1997, 1998), this pathogen has not been reported on peach in China. The aim of the present study is to identify and characterize Diaporthe species associated with diseased peach trees in Jinshui Experimental Orchard in Hubei Academy of Agriculture Sciences in Hubei Province, China, based on morphological, molecular and pathological characteristics

\section{Materials \& Methods}

\section{Isolation}

Diseased trunk parts and shoots of $P$. persica showing dieback symptoms were collected from Jinshui Experimental Orchard in Hubei Academy of Agriculture Sciences in Hubei Province (Fig. 1). Tissue pieces $(5 \times 5 \mathrm{~mm})$ were collected from the margin of shoot lesions and were surfacesterilized by consecutive immersion in a $75 \%$ ethanol solution for $1 \mathrm{~min}$ and a $5 \%$ sodium hypochlorite solution for $30 \mathrm{~s}$, followed by rinsing in sterile distilled water for $1 \mathrm{~min}$. The pieces were dried with sterilized paper towels and placed on potato dextrose agar (PDA) plates amended with ampicillin $(0.1 \mathrm{~g} / \mathrm{l})$. The plates were incubated at $28{ }^{\circ} \mathrm{C}$ for at least 5 days or until fungal mycelia were observed growing from the symptomatic tissues. Putative isolates growing out from the tissues with a colony morphology that resembled Diaporthe taxa were subcultured on fresh PDA plates and incubated at $28{ }^{\circ} \mathrm{C}$ until sporulation. Conidiomata on PDA were crushed and plated on water agar (WA). Pure cultures were obtained by placing single germinating spores in fresh PDA plates.

\section{Morphological characterization}

To induce sporulation, isolates on PDA were inoculated using double autoclaved toothpicks. Isolates were induced to sporulate by growing them on PDA bearing double-autoclaved toothpicks. Inoculated plates were incubated at $28{ }^{\circ} \mathrm{C}$ under a 12-hour light-darkness regime for 3-4 weeks to enhance sporulation. Microscopic structures were mounted in water on glass slides for light microscopy, and colony colors were assessed according to the charts of Rayner (1970). Thirty conidia were measured; the minimum and maximum ranges of the spore dimensions were recorded, and the average values were calculated. The pure isolates were cultured on PDA plates and dried on sterilized filter paper for storage at $-20{ }^{\circ} \mathrm{C}$. An Axio Imager Z2 Photographic Microscope (Carl Zeiss Microscopy, Germany) was used for observations and photographing of the fungal structures, and measurements $(\times 40, \times 100)$ were made with ZEN PRO 2012 software (Carl Zeiss Microscopy, Germany). Ex-type living cultures were deposited in the MFLUCC culture collection, and dried herbarium materials were deposited in the herbarium (MFLU) at Mae Fah Luang University, Thailand. Representative isolates were deposited in the China General Microbiological Culture Collection Center (CGMCC) (Table 1).

\section{DNA extraction, PCR amplification and sequencing}

Isolates were grown on PDA and incubated at $28{ }^{\circ} \mathrm{C}$ for $7 \mathrm{~d}$. Genomic DNA was extracted following the CTAB method used by Udayanga et al. (2012). The primer pair ITS1/ITS4 was used to amplify the ITS region following the procedure described by White et al. (1990). The primer pair EF1-728F/EF1-986R (Carbone \& Kohn 1999) was used to amplify a partial fragment of the EF1- $\alpha$ gene. The primer pair Bt2a/Bt2b (Glass \& Donaldson 1995) was used to amplify $\beta$-tubulin (BT). The primer pair CAL228F/CAL737R (Carbone \& Kohn 1999) was used to amplify the calmodulin (CAL) gene. Polymerase chain reaction (PCR) was performed in a BIORAD $1000^{\mathrm{TM}}$ thermal cycler in a total volume of $25 \square 1$. The PCR mixture contained $0.3 \square 1$ of TaKaRa Ex-Taq DNA polymerase, 
$12.5 \square 1$ of $2 \times$ PCR buffer with $2.5 \square 1$ of dNTPs, $1 \square 1$ of each primer, $9.2 \square 1$ of double-distilled water and 100-500 ng of DNA template. DNA samples were detected by electrophoresis and ethidium bromide (EB) staining and used as templates for PCR amplification. DNA sequencing was performed by the Sunbiotech Company, Beijing, China.

\section{Sequence alignment and phylogenetic analyses}

The sequences obtained in this study were aligned with sequences retrieved from GenBank (Table 1) using MAFFT (http://www.ebi.ac.uk/Tools/msa/mafft/) (Katoh \& Toh 2010) and were manually optimized with BioEdit (Hall 2006) to allow maximum alignment. Two separate phylogenetic trees were constructed. All available type sequences of Diaporthe species were included in a preliminary multigene phylogenetic analysis (ITS, EF1- $\alpha, \mathrm{BT}, \mathrm{CAL}$ ) to identify the close relatives of the strains included in this study (data not shown). Phylogenetically closely related species were selected for further analysis of the combined ITS, EF1- $\alpha$, BT and CAL regions (Fig. 2). Maximum parsimony analysis (MP) was performed using phylogenetic analysis using parsimony (PAUP v. 4.0b10) (Swofford 2003). Ambiguously aligned regions were excluded from all analyses and gaps were treated as missing data. Trees were inferred using the heuristic search option with TBR branch swapping and 1000 random sequence additions. Branches of zero length were collapsed, and all equally most parsimonious trees were saved. Descriptive tree statistics such as the tree length [TL], consistency index [CI], retention index [RI], rescaled consistency index [RC], and homoplasy index $[\mathrm{HI}]$ were calculated. The trees were visualized with TreeView v. 1.6.6 (Page 1996).

For the Bayesian analyses, the models of evolution were estimated using MrModeltest v. 2.3 (Nylander 2004). The best fitting model (HKY + I + G) was selected for the ITS, EF1- $\alpha$, BT and CAL sequence datasets. Posterior probabilities (PP) were determined by Bayesian Markov Chain Monte Carlo (BMCMC) sampling in MrBayes 3.0b4 (Ronquist \& Huelsenbeck 2003), using the estimated model of evolution. Six simultaneous Markov chains were run for 1,000,000 generations, and trees were sampled every 100th generation (resulting in 10,000 total trees). The first 2000 trees, which represented the burn-in phase of the analyses, were discarded and the remaining 8000 trees were used to calculate PP in the majority-rule consensus tree. The sequences generated in this study were deposited in GenBank (Table 1), the sequence alignment was submitted to Tree BASE (www.treebase.org, http://purl.org/phylo/treebase/phylows/study/TB2:S18948?x-

accesscode=e2e3debfea37466bec70ff5ea93cae0\&format=html submission no.: S19640), and taxonomic novelties were submitted to the Faces of fungi database (Jayasiri et al. 2015) and Index Fungorum (Index Fungorum 2016).

\section{Pathogenicity testing}

Pathogenicity of six representative Diaporthe isolates (Table 1) was tested on detached healthy peach shoots. As the D. eres Nitschke isolates generated in this study clustered in three different clades in the phylogenetic analysis, we selected three representative isolates from each clade of the D. eres complex for the pathogenicity test. The isolates were grown on PDA at $28^{\circ} \mathrm{C}$. for five days prior to inoculation. Peach shoots, $8-10 \mathrm{~mm}$ in diameter and $30 \mathrm{~cm}$ long, were collected from healthy mature peach cv. 'Beijing No. 40 ' in an orchard at the Institute of Forestry and Pomology, Beijing Academy of Agriculture and Forestry Sciences in Beijing. All leaves were removed and the shoots were surface-sterilized with $70 \%$ ethanol prior to inoculation. Twigs were wounded with a sterilized scalpel, and a 5-mm-diam. mycelium agar plug was placed on the wound. The inoculated wounds were wrapped with Parafilm (BEMIS, USA) to prevent desiccation and contamination. Control shoots were inoculated with sterile PDA plugs. Twelve shoots were inoculated per isolate. The inoculated shoots and controls were maintained at $28{ }^{\circ} \mathrm{C}$ in a growth chamber under artificial light (12/12 h light/dark cycle) at $80 \%$ relative humidity (RH). Disease symptoms were checked daily for six weeks following inoculation, and the lesion length was measured after 18, 30 and 42 days using a digital caliper calibrated for $\mathrm{mm}$. At the end of the experiment pieces of tissue from the lesion area were transferred to PDA plates to re-isolate the pathogen. Significance of differences in the lesion lengths between the treatments were determined by one-way ANOVA, and the means were compared using Duncan's multiple range test at the $5 \%$ confidence level. SPSS software v. 17 (SPSS Inc., Chicago, IL) was used for the statistical tests. 
Table 1 Diaporthe species analysed in this study (Fig. 2). All type species are in bold and newly deposited sequences are in italic.

\begin{tabular}{|c|c|c|c|c|c|c|c|c|}
\hline \multirow[t]{2}{*}{ Species } & \multirow[t]{2}{*}{ Strain } & \multirow[t]{2}{*}{ Host } & \multirow[t]{2}{*}{ Locality } & \multirow[t]{2}{*}{ Collector } & \multicolumn{4}{|c|}{ GenBank Accession numbers } \\
\hline & & & & & ITS & CAL & EF1- $\alpha$ & BT \\
\hline Diaporthe alleghaniensis & CBS 495.72 & Betula alleghaniensis & Canada & R.H. Arnold & KC343007 & KC343249 & KC343733 & KC343975 \\
\hline D. alnea & CBS 146.46 & Alnus sp. & Netherlands & S. Truter & KC343008 & KC343250 & KC343734 & KC343976 \\
\hline D. amygdali & CBS 115620 & Prunus persica. & Georgia, USA & W. Uddin & KC343020 & KC343262 & KC343746 & KC343988 \\
\hline D. amygdali & CBS 120840 & Prunus salicina & South Africa & U. Damm & KC343021 & KC343263 & KC343747 & KC343989 \\
\hline D. amygdali & CBS 126679 & Prunus dulcis. & Portugal & E. Diogo & KC343022 & KC343264 & KC343748 & KC343990 \\
\hline D. amygdali & CBS 126680 & Prunus dulcis & Portugal & E. Diogo & KC343023 & KC343265 & KC343749 & KC343991 \\
\hline D. aquatica & IFRDCC 3051 & Aquatic habitat & China & - & JQ797437 & - & - & - \\
\hline D. arecae & CBS 161.64 & Areca catechu & India & H.C. Srivastava & KC343032 & KC343274 & KC343758 & KC344000 \\
\hline D. arengae & CBS 114979 & Arenga engleri & Hong Kong & K.D. Hyde & KC343034 & KC343276 & KC343760 & KC344002 \\
\hline D. baccae & CBS 136972 & $\begin{array}{l}\text { Vaccinium } \\
\text { corymbosum }\end{array}$ & - & - & KJ160565 & - & KJ160597 & - \\
\hline D. bicincta & CBS 121004 & Juglans sp. & Tennessee, USA & L. Vasilyeva & KC343134 & KC343376 & KC343860 & KC344102 \\
\hline D. biguttusis & CGMCC 3.17081 & Lithocarpus glabra & China & Wei Sun & KF576282 & - & KF576257 & KF576306 \\
\hline D. celastrina & CBS 139.27 & Celastrus scandens & - & L.E. Wehmeyer & KC343047 & KC343289 & KC343773 & KC344015 \\
\hline D. cf. nobilis & CBS 200.39 & Laurus nobilis & Germany & Kotthoff & KC343151 & KC343393 & KC343877 & KC344119 \\
\hline D. cf. nobilis & CBS 113470 & Castanea sativa & South Korea & K.A. Seifert & KC343146 & KC343388 & KC343872 & KC344114 \\
\hline D. cf. nobilis & CBS 116953 & Pyrus pyrifolia & New Zealand & W. Kandula & KC343147 & KC343389 & KC343873 & KC344115 \\
\hline D. cf. nobilis & CBS 124030 & Malus pumila & New Zealand & G.J. Samuels & KC343149 & KC343391 & KC343875 & KC344117 \\
\hline D. cf. nobilis & CBS 129167 & Rhododendron sp. & Latvia & I. Apine & KC343150 & KC343392 & KC343876 & KC344118 \\
\hline D. cf. nobilis & CBS 587.79 & Pinus pantepella & Japan & G. H. Boerema & KC343153 & KC343395 & KC343879 & KC344121 \\
\hline D. citri & CBS 135422 & Citrus sp. & USA, Florida & L.W. Timmer & KC843311 & KC843157 & KC843071 & KC843187 \\
\hline D. citrichinensis & ZJUD34 & Citrus sp. & China & F. Huang & JQ954648 & KC357494 & JQ954666 & - \\
\hline D. compacta & CGMCC 3.17536 & Camellia sinensis & China & - & KP267854 & - & KP267928 & KP293434 \\
\hline D. diospyricola & СРC 21169 & Diospyros whyteana & South Africa & P.W. Crous & KF777156 & - & - & - \\
\hline D. ellipicola & CGMCC 3.17084 & Lithocarpus glabra & China & Wei Sun & KF576270 & - & KF576245 & KF576291 \\
\hline D. eres & AR5193 & Ulmus sp. & Germany & R. Schumacher & KJ210529 & KJ434999 & KJ210550 & KJ420799 \\
\hline D. eres & AR3560 & Viburnum lantana & Austria & Walter Jaklitsch & JQ807425 & KJ435011 & JQ807351 & KJ420795 \\
\hline D. eres & AR3723 & Rubus fruticosus & Austria & Walter Jaklitsch & JQ807428 & KJ435024 & JQ807354 & KJ420793 \\
\hline D. eres & AR4355 & Prunus sp. & Korea & Su-Ki Hong & JQ807433 & KJ435035 & JQ807359 & KJ420797 \\
\hline D. eres & AR4373 & Ziziphus jujuba & Korea & Su-Ki Hong & JQ807442 & KJ435013 & JQ807368 & KJ420798 \\
\hline D. eres & AR5223 & Acer negundo & Germany & R. Schumacher & KJ210528 & KJ435000 & KJ210549 & KJ420830 \\
\hline D. eres & DLR12a & Vitis vinifera & France & P. Larignon & KJ210518 & KJ434996 & KJ210542 & KJ420783 \\
\hline D. eres & DP0666 & Juglans cinerea & USA & S. Anagnostakis & KJ210522 & KJ435007 & KJ210546 & KJ420788 \\
\hline
\end{tabular}


Table 1 Continued.

\begin{tabular}{|c|c|c|c|c|c|c|c|c|}
\hline \multirow[t]{2}{*}{ Species } & \multirow[t]{2}{*}{ Strain } & \multirow[t]{2}{*}{ Host } & \multirow[t]{2}{*}{ Locality } & \multirow[t]{2}{*}{ Collector } & \multicolumn{4}{|c|}{ GenBank Accession numbers } \\
\hline & & & & & ITS & CAL & EF1- $\alpha$ & BT \\
\hline D. eres & FAU483 & Malus sp. & Netherlands & F.A. Uecker & KJ210537 & KJ435022 & JQ807422 & KJ420827 \\
\hline D. eres & FAU506 & Cornus florida & USA & F.A. Uecker & KJ210526 & KJ435012 & JQ807403 & KJ420792 \\
\hline D. eres & FAU532 & Chamaecyparis sp. & USA & F.A. Uecker & JQ807333 & KJ435015 & JQ807408 & KJ420815 \\
\hline D. eres & LCM11401a & Ulmus sp. & USA & L. Mejia & $\mathrm{KJ} 210521$ & KJ435027 & $\mathrm{KJ} 210545$ & KJ420787 \\
\hline D. eres & MFLUCC 16-0097 & Prunus persica & Hubei, China & X. H. Li & KU557547 & KU557595 & KU557615 & KU557571 \\
\hline D. eres & MFLUCC 16-0098 & Prunus persica & Hubei, China & X. H. Li & KU557548 & KU557596 & KU557616 & KU557572 \\
\hline D. eres & MFLUCC 16-0099 & Prunus persica & Hubei, China & X. H. Li & KU557549 & KU557597 & KU557617 & $K U 557573$ \\
\hline D. eres & MFLUCC 16-0100 & Prunus persica & Hubei, China & X. H. Li & KU557550 & KU557598 & KU557618 & KU557574 \\
\hline D. eres & MFLUCC 16-0101 & Prunus persica & Hubei, China & X. H. Li & KU557551 & KU557599 & KU557619 & $K U 557575$ \\
\hline D. eres & MFLUCC 16-0102 & Prunus persica & Hubei, China & X. H. Li & KU557552 & KU557600 & KU557620 & $K U 557576$ \\
\hline D. eres & MFLUCC 16-0103 & Prunus persica & Hubei, China & X. H. Li & KU557553 & KU557601 & KU557621 & KU557577 \\
\hline D. eres & MFLUCC 16-0104 & Prunus persica & Hubei, China & X. H. Li & KU557554 & KU557602 & KU557622 & KU557578 \\
\hline D. eres & MFLUCC 16-0109 & Prunus persica & Hubei, China & X. H. Li & KU557559 & KU557607 & KU557627 & KU557583 \\
\hline D. eres & MFLUCC 16-0110 & Prunus persica & Hubei, China & X. H. Li & KU557560 & KU557608 & KU557628 & KU557584 \\
\hline D. eres & MFLUCC 16-0111 & Prunus persica & Hubei, China & X. H. Li & KU557561 & KU557609 & KU557629 & KU557585 \\
\hline D. eres & MFLUCC 16-0112 & Prunus persica & Hubei, China & X. H. Li & KU557562 & KU557610 & KU557630 & KU557586 \\
\hline D. foeniculacea & CBS 171.78 & Foeniculum vulgare & Spain & A.J.L. Phillips & KC343101 & KC343343 & KC343827 & KC344069 \\
\hline D. gulyae & BRIP 54025 & Helianthus annuus & Australia & - & JF431299 & - & JN645803 & - \\
\hline D. helicis & AR5211 & Hedera helix & Germany & R. Schumacher & KJ210538 & KJ435043 & KJ210559 & KJ420828 \\
\hline D. hongkongensis & CBS 115448 & Dichroa febrífuga & Hong Kong & K. D. Hyde & KC343119 & KC343361 & KC343845 & KC344087 \\
\hline D. longicicola & CGMCC 3.17089 & Lithocarpus glabra & China & Wei Sun & KF576267 & - & KF576242 & KF576291 \\
\hline D. mahothocarpus & CGMCC 3.15181 & Lithocarpus glabra & China & Wei Sun & KC153096 & - & KC153087 & KF576312 \\
\hline D. momicola & MFLUCC 16-0113 & Prunus persica & Hubei, China & X. H. Li & KU557563 & KU557611 & KU557631 & KU557587 \\
\hline D. momicola & MFLUCC 16-0114 & Prunus persica & Hubei, China & X. H. Li & KU557564 & KU557612 & KU557632 & KU557588 \\
\hline D. momicola & MFLUCC 16-0115 & Prunus persica & Hubei, China & X. H. Li & KU557565 & KU557613 & KU557633 & KU557589 \\
\hline D. momicola & MFLUCC 16-0116 & Prunus persica & Hubei, China & X. H. Li & KU557566 & KU557614 & KU557634 & KU557590 \\
\hline D. neilliae & CBS 144.27 & Spiraea sp. & - & L.E. Wehmeyer & KC343144 & KC343386 & KC343870 & KC344112 \\
\hline D. padi var. padi & CBS 114200 & Prunus padus & Sweden & K. \& L. Holm & KC343169 & KC343411 & KC343895 & KC344137 \\
\hline D. penetriteum & LC3215 & Camellia sinensis & China & F. Liu & KP267879 & - & KP267953 & KP293459 \\
\hline D. pescicola & MFLUCC 16-0105 & Prunus persica & Hubei, China & X. H. Li & KU557555 & KU557603 & KU557623 & KU557579 \\
\hline D. pescicola & MFLUCC 16-0106 & Prunus persica & Hubei, China & X. H. Li & KU557556 & KU557604 & KU557624 & KU557580 \\
\hline D. pescicola & MFLUCC 16-0107 & Prunus persica & Hubei, China & X. H. Li & KU557557 & KU557605 & KU557625 & KU557581 \\
\hline D. pescicola & MFLUCC 16-0108 & Prunus persica & Hubei, China & X. H. Li & KU557558 & KU557606 & KU557626 & KU557582 \\
\hline D. phragmitis & CBS 138897 & Phragmites australis & Beijing, China & P.W. Crous & KP004445 & - & - & KP004507 \\
\hline D. pseudomangiferae & CBS 101339 & Mangifera indica & Dominican Republic & P. de Leeuw & KC343181 & KC343423 & KC343907 & KC344149 \\
\hline D. pseudophoenicicola & CBS 462.69 & Phoenix dactylifera & Spain & H.A. van der Aa & KC343184 & KC343426 & KC343910 & KC344152 \\
\hline
\end{tabular}


Table 1 Continued.

\begin{tabular}{|c|c|c|c|c|c|c|c|c|}
\hline \multirow[t]{2}{*}{ Species } & \multirow[t]{2}{*}{ Strain } & \multirow[t]{2}{*}{ Host } & \multirow[t]{2}{*}{ Locality } & \multirow[t]{2}{*}{ Collector } & \multicolumn{4}{|c|}{ GenBank Accession numbers } \\
\hline & & & & & ITS & CAL & EF1- $\alpha$ & BT \\
\hline D. psoraleae-pinnatae & CBS 136413 & Psoralea pinnata & South Africa & M.J. Wingfield & KF777159 & - & - & KF777252 \\
\hline D. pterocarpicola & MFLUCC 10-0580 & Pterocarpus indicus & Thailand & D. Udayanga & JQ619887 & JX197433 & JX275403 & JX275441 \\
\hline D. pulla & CBS 338.89 & Hedera helix & Croatia & M. Cvetkovic & KC343152 & KC343394 & KC343878 & KC344120 \\
\hline D. pustulata & CBS 109784 & Prunus padus & Austria & A.Y. Rossman & KC343187 & KC343429 & KC343913 & KC344155 \\
\hline D. taoicola & MFLUCC 16-0117 & Prunus persica & Hubei, China & X. H. Li & KU557567 & - & KU557635 & KU557591 \\
\hline D. taoicola & MFLUCC 16-0118 & Prunus persica & Hubei, China & X. H. Li & KU557568 & - & KU557636 & KU557592 \\
\hline D. taoicola & MFLUCC 16-0119 & Prunus persica & Hubei, China & X. H. Li & KU557569 & - & KU557637 & KU557593 \\
\hline D. taoicola & MFLUCC 16-0120 & Prunus persica & Hubei, China & X. H. Li & KU557570 & - & KU557638 & KU557594 \\
\hline D. terebinthifolii & CBS 133180 & Schinus terebinthifolius & Brazil & J. Lima & KC343216 & KC343458 & KC343942 & KC344184 \\
\hline D. vaccini & CBS 160.32 & Oxycoccus macrocarpos & USA & C.L. Shear & KC343228 & KC343470 & КC343954 & КC344196 \\
\hline D. virgiliae & CMW 40748 & Virgilia oroboides & South Africa & - & KP247566 & - & - & KP247575 \\
\hline Phomopsis castaneae & DNP128 & Castaneae mollissimae & China & S.X. Jiang & JF957786 & KJ435040 & KJ210561 & KJ420801 \\
\hline P. cotoneastri & CBS 439.82 & Cotoneaster sp. & UK & H. Butin & FJ889450 & JX197429 & GQ250341 & JX275437 \\
\hline P. fukushii & AR4349 & Vitis vinifera & Korea & S.K. Hong & JQ807432 & KJ435032 & JQ807358 & KJ420822 \\
\hline P. fukushii & AR4369 & Pyrus pyrifolia & Korea & S. K. Hong & JQ807440 & KJ435005 & JQ807366 & KJ420813 \\
\hline P. fukushii & DP0177 & Pyrus pyrifolia & New Zealand & W. Kandula & JQ807381 & KJ435041 & JQ807450 & KJ420820 \\
\hline P. fukushii & MAFF 625029 & Pyrus pyrifolia & Japan & S. Kanematsu & JQ807466 & KJ435002 & JQ807415 & KJ420808 \\
\hline Diaporthella corylina & CBS 121124 & Corylus sp. & China, Fuyuan & L.N. Vassiljeva & KC343004 & КC343246 & KC343730 & КC343972 \\
\hline
\end{tabular}

\section{Results}

\section{Field survey}

Numerous diseased P. persica individuals were observed in Jinshui Experimental Orchard in Hubei Academy of Agriculture Sciences in Hubei Province in summer 2015 (May to August). Trees showing dieback symptoms that corresponded to extensive wood necrosis were detected. Declining trees exhibited a variety of symptoms including exudation of gums that gradually formed a brownish, gluey mass on the branches and trunk. On older cankers, the bark surface was sunken with the overlying bark appearing cracked and necrotic. In addition, several trees displayed symptoms of sudden death (Fig. 1)

\section{DNA phylogeny}

DNA sequences and multi-locus phylogenetic analyses allowed the identification of four different species in this study, including D. eres and three distinct Diaporthe species that did not group with any described Diaporthe species from GenBank. The combined ITS, EF1- $\alpha$, BT and CAL datasets of these phylogenetically closely related species consisted of 2066 characters (ITS: 1-561, EF1- $\alpha$ : 562-1000, BT: 1001-1534 and CAL: 1535-2066 - including alignment gaps) for 87 ingroup and 1 outgroup taxa. Of the 2066 characters, 1080 were constant and 344 were variable and parsimony uninformative. Maximum parsimony analysis of the remaining 654 parsimonyinformative characters resulted in 10 most parsimonious trees $(\mathrm{TL}=2830 ; \mathrm{CI}=0.309, \mathrm{RI}=0.751, \mathrm{RC}=0.232, \mathrm{HI}=0.691)$, 


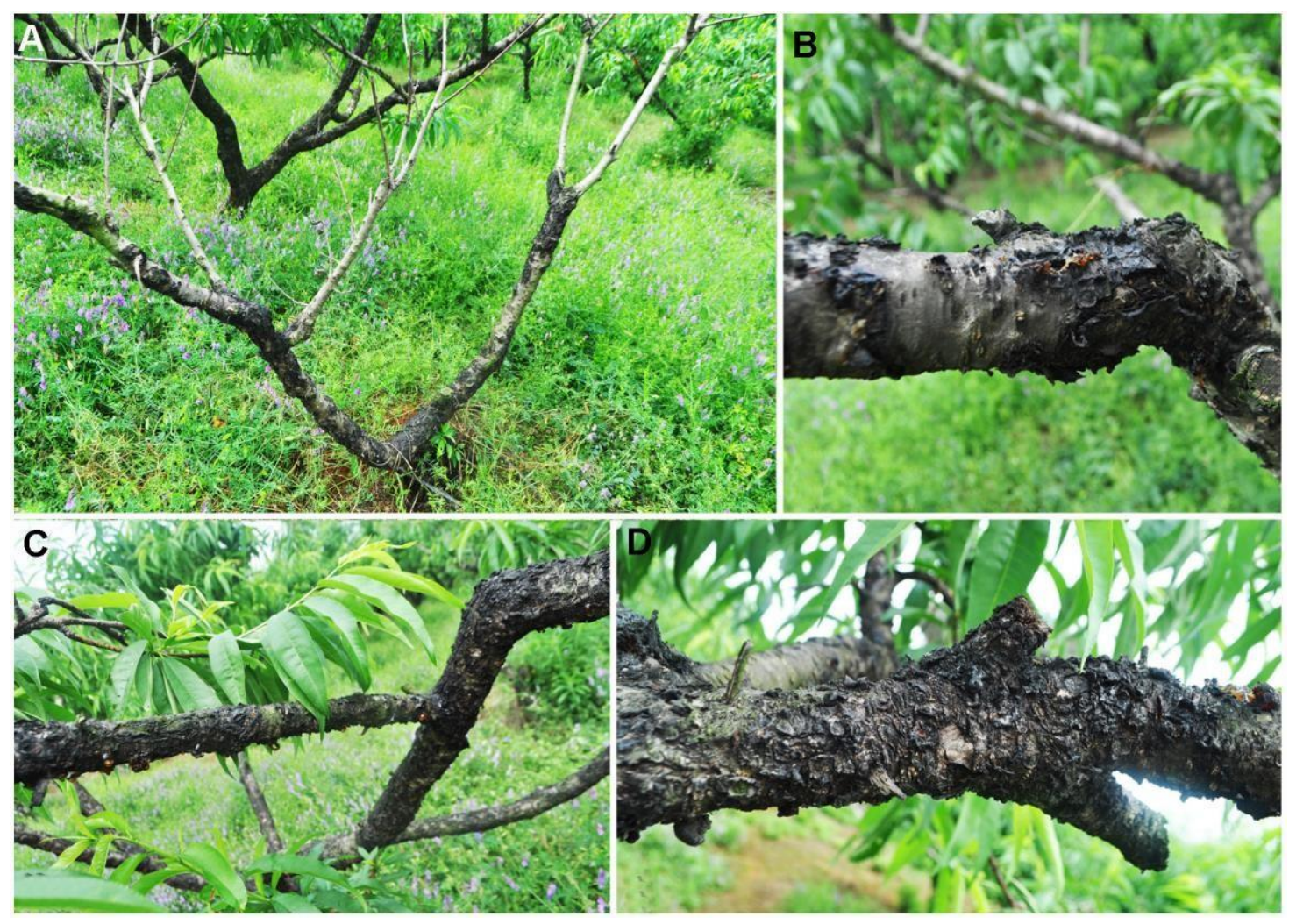

Figure 1 - Field symptoms. A, Dying peach tree in the orchard; B-D, Dieback symptoms of trunk and branches.

and the best tree is shown in Fig. 2. Essentially, a similar tree was obtained from the Bayesian analysis. The three new species appeared in three distinct clades with high bootstrap support values (Fig. 2).

\section{Taxonomy}

Three previously undescribed species of Diaporthe were identified from the DNA sequence analysis together with cultural morphology and a description of asexual structures. Although none of the new fungi produced sexual structures in culture, all have been described in the Diaporthe genus according to the rules in the International Code of Nomenclature for algae, fungi and plants (Maharachchikumbura et al. 2015, Rossman et al. 2015) on the basis that Diaporthe was established 14 years before Phomopsis, in agreement with previous studies.

\section{Diaporthe eres Nitschke}

Material examined - China, Hubei Province, on diseased shoots of $P$. persica, June 2015, XingHong Li (MFLUCC 16-0097 to MFLUCC 16-0104 and MFLUCC 16-0109 to MFLUCC 16-0112)

Diaporthe momicola Dissanayake, X.H. Li \& K.D. Hyde, sp. nov.

Fig. 3

Indexfungorum number: IF 551987; Facesoffungi number: FoF 01958

Etymology - momo, referring to peach in Japanese.

Holotype - MFLU 16-0905

Pathogenic on Prunus persica shoots. Sexual morph: Not observed. Asexual morph: Conidiomata up to $350 \mu \mathrm{m}$ diam., formed on PDA and sterilized tooth picks after 4 weeks, solitary or in groups of dark stroma with a sharp, slightly raised and blackened margin, with black cylindrical ostiolate necks up to 1.5 $\mathrm{mm}$, subglobose. Conidiophores reduced to conidiogenous cells. Alpha conidia $6.5-9.5 \times 1.5-2 \mu \mathrm{m}(x=8 \times$ $2 \mu \mathrm{m}$ ) hyaline, smooth, biguttulate, fusiform to oval, tapered at both ends, cylindrical to ellipsoidal. Beta conidia $20-32 \times 1-1.5 \mu \mathrm{m}(*=25 \times 1.5 \mu \mathrm{m})$ scattered among the alpha conidia.

Culture characteristics - Colonies on PDA covering the entire Petri dishes after 10 days, ropey with abundant tufted white aerial mycelium, buff, numerous black conidiomata less than $0.5 \mathrm{~mm}$ diam. form in the mycelium mostly towards the edge of the colony; reverse buff with zonate and irregular lines corresponding to embedded conidiomata. 


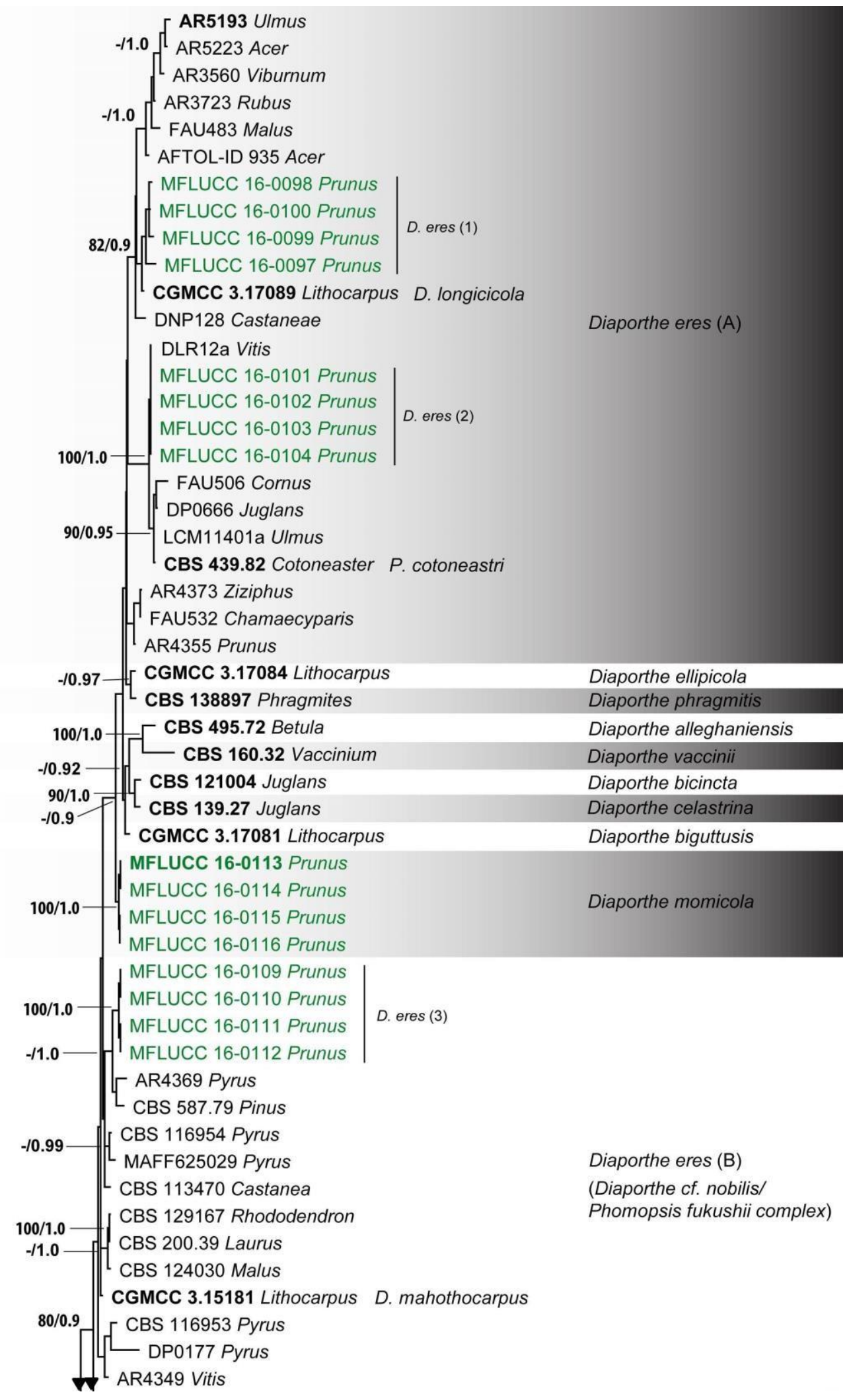

Figure 2 - Phylogram generated from Maximum Parsimony analysis of Diaporthe species isolated in this study and their phylogenetically closely related species based on combined ITS, EF1- $\alpha$, BT and CAL sequence data. Parsimony bootstrap support values for MP $\geq 75 \%$ and Bayesian posterior probabilities $\geq 0.9$ are indicated above the nodes. The tree is rooted with Diaporthella corylina (CBS 121124). Isolate numbers of ex-types and reference strains are in bold. Taxa isolated in this study are in green and the ex-type isolate numbers of novel species are in bold. 


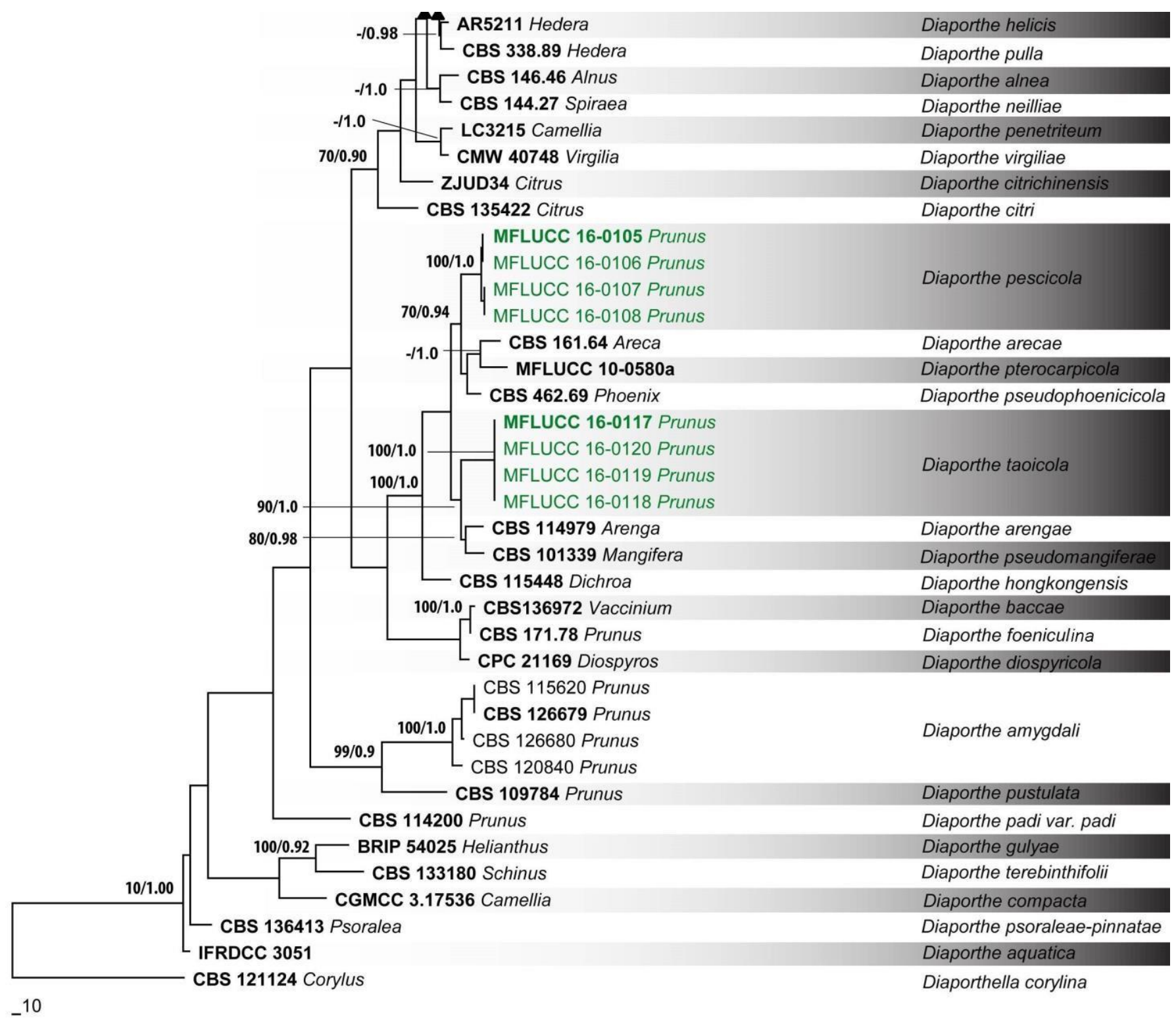

Figure 2 - Continued.

Material examined - CHINA, Hubei Province, on diseased shoots of P. persica (Rosaceae), May 2015, XingHong Li; (MFLU 16-0905, holotype); ex-type living culture MFLUCC 160113=CGMCC 3.17466 .

Notes - Diaporthe momicola was isolated from diseased peach shoots in Jinshui Experimental Orchard, Hubei Province. Four strains of D. momicola clustered in a well-supported clade close to $D$. biguttusis Y. H. Gao \& L. Cai, D. alleghaniensis Udayanga, Crous \& K.D. Hyde and D. vaccinii Shear (Fig. 2). Phylogenetically, D. biguttusis is the closest species to D. momicola, differing by 18 nucleotides in the concatenated alignment, in which 11 were distinct in the ITS region, 2 in the EF1- $\alpha$ region and 5 in BT region. Since no CAL sequence was available for $D$.

biguttusis nucleotide differences could not compared with those of D. momicola.

Diaporthe pescicola Dissanayake, X.H. Li \& K.D. Hyde, sp. nov.

Fig. 3

Index fungorum number: IF 551988; Facesoffungi number: FoF 01959

Etymology - pesca, referring to peach in Italian.

Holotype - MFLU 16-0906

Pathogenic on Prunus persica shoots. Sexual morph: Not observed. Asexual morph:

Conidiomata up to $300 \mathrm{~mm}$ in diam., superficial, solitary, scattered on PDA, globose, dark brown to black, clustered in groups of 2-5 pycnidia. Conidiophores $21-35 \times 1.5-2.5 \mu \mathrm{m}(*=27 \times 2 \mu \mathrm{m})$, cylindrical, aseptate, densely aggregated, straight or sinuous, terminal, slightly tapered towards the apex. Alpha conidia $6-8.5 \times 2-$ 
$3 \mu \mathrm{m}(*=8 \times 3 \mu \mathrm{m})$ hyaline, biguttulate, fusiform or oval, both ends obtuse. Beta conidia $18-37 \times 1-1.5 \mu \mathrm{m}$ $(x=27 \times 1.5 \mu \mathrm{m})$ hyaline, aseptate, filiform, hamate, guttulate, tapering towards both ends.

Culture characteristics - Colonies on PDA covering entire Petri dishes after 10 days, grey, with scant aerial mycelium; reverse fuscous black.

Material examined - CHINA, Hubei Province, on diseased shoots of P. persica (Rosaceae), May 2015, XingHong Li; (MFLU 16-0906, holotype); ex-type living culture MFLUCC $160105=$ CGMCC 3.17465 .

Notes - Diaporthe pescicola occurs in a clade separate from D. arecae H.C. Srivast., Zakia \& Govindar., D. pterocarpicola Udayanga, X.Z. Liu and K.D. Hyde and D. pseudophoenicicola Gomes, C. Glienke \& Crous. Diaporthe pescicola differs from D. arecae, D. pterocarpicola and D. pseudophoenicicola in the presence of beta conidia. Phylogenetically, D. pseudophoenicicola is the closest species to $D$. pescicola (Fig. 2), differing by 47 nucleotides in the concatenated alignment, in which 5 were distinct in the ITS region, 14 in the EF1- $\alpha$ region, 16 in the BT region and 12 in the CAL region.
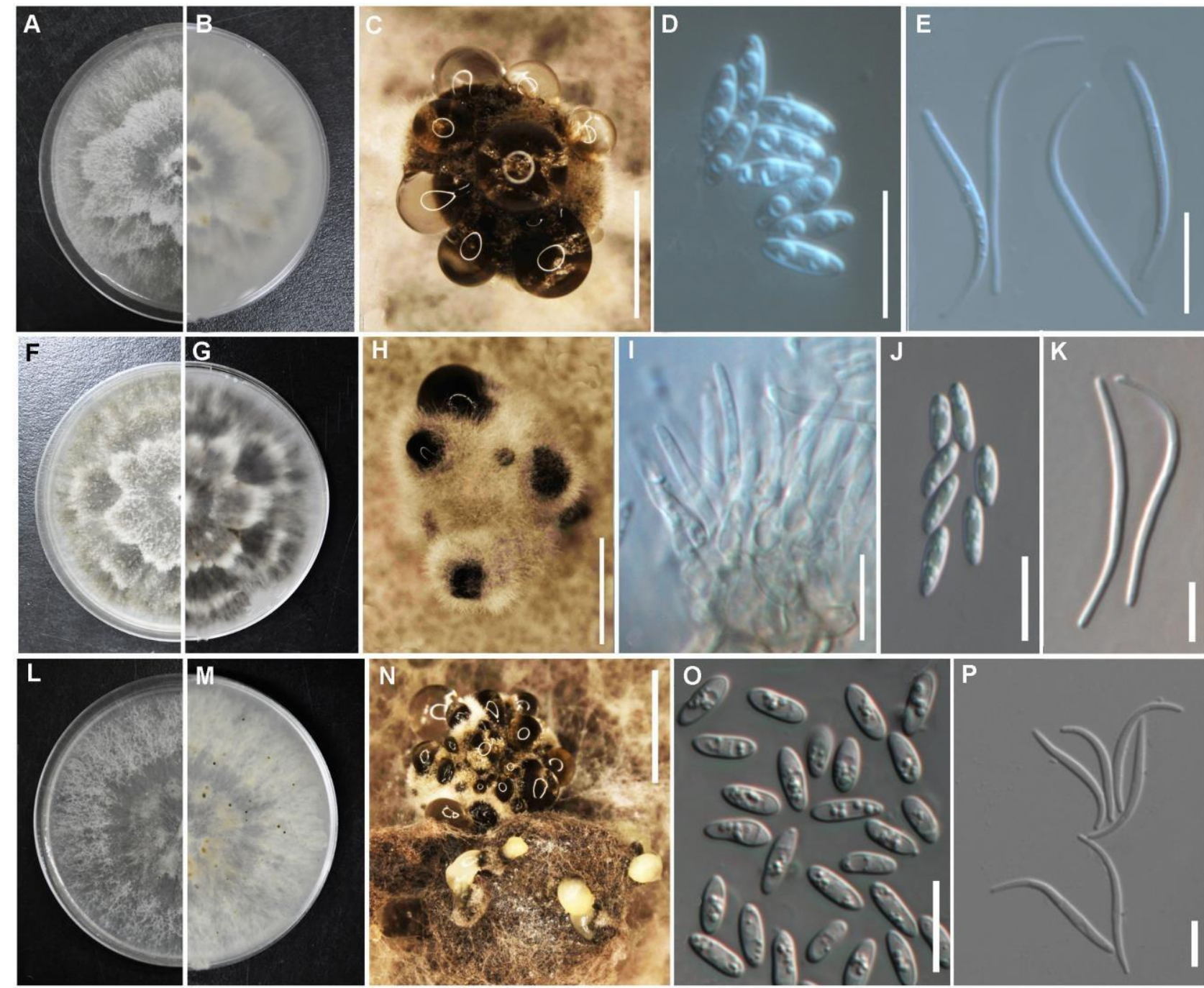

Figure 3 - Diaporthe momicola (ex-type MFLUCC 16-0113, A-E), D. pescicola (ex-type MFLUCC 160105, F-K), D. taoicola (ex-type MFLUCC 16-0117, L-P). A,B, Culture on PDA after 2 weeks. C, Conidial ooze. D, Alpha conidia. E, Beta conidia. F, G, Culture on PDA after 2 weeks. H, Conidial ooze. I, Conidiophores. J, Alpha conidia. K, Beta conidia. L, M, Culture on PDA after 2 weeks. N, Conidial ooze. O, Alpha conidia. P, Beta conidia. Scale bars, $\mathrm{C}=200 \mu \mathrm{m} ; \mathrm{D}, \mathrm{E}=10 \mu \mathrm{m} ; \mathrm{H}=200 \mu \mathrm{m} ; \mathrm{I}=20 \mu \mathrm{m} ; \mathrm{J}, \mathrm{K}=10 \mu \mathrm{m}$; $\mathrm{N}=200 \mu \mathrm{m} ; \mathrm{O}, \mathrm{P}=10 \mu \mathrm{m}$.

Diaporthe taoicola Dissanayake, X.H. Li \& K.D. Hyde, sp. nov.

Fig.3

Index fungorum number: IF 551989; Facesoffungi number: FoF 01960

Etymology - tao, referring to peach in Chinese.

Holotype - MFLU 16-0907 
Pathogenic on Prunus persica shoots. Sexual morph: Not observed. Asexual morph: Conidiomata up to $300 \mu \mathrm{m}$ diam., pycnidial, sporulating profusely on PDA, globose, multi-locular, black, semi-immersed, cream conidial droplets exuding from central ostioles, walls consisting of 3-6 layers of textura angularis. Conidiophores 10-25 $\times 2-3 \mu \mathrm{m}$ hyaline, smooth, densely aggregated, cylindrical, straight to sinuous. Conidiogenous cells $9-16 \times 1.5-2 \mu \mathrm{m}$, phialidic, cylindrical, terminal and lateral, with a slight taper towards the apex. Paraphyses hyaline, smooth, 1-3-septate, cylindrical with obtuse ends, extending above conidiophores. Alpha conidia $7-9 \times 2-3 \mu \mathrm{m}(x=8 \times 3 \mu \mathrm{m})$ hyaline, smooth, guttulate, fusoid to ellipsoid, tapering towards both ends, straight, apex subobtuse, base bluntly rounded with flattened hilum. Beta conidia $20-25 \times 1.5-2 \mu \mathrm{m}(*=19 \times 2 \mu \mathrm{m})$ hyaline, spindle-shaped, aseptate, smooth, apex subacutely rounded, base truncate, tapering towards apex, curved.

Culture characteristics - Colonies covering Petri dishes after 2 weeks in the dark at $25^{\circ} \mathrm{C}$. On PDA, having patches of dirty white and umber, reverse with patches of umber.

Material examined - CHINA, Hubei Province, on diseased shoots of P. persica (Rosaceae), July 2015, XingHong Li (MFLU 16-0907, holotype); ex-type living culture MFLUCC 160117=CGMCC 3.17464 .

Notes - This novel species occurs in a clade separate from $D$. arecae, D. arengae R.R. Gomes, C. Glienke \& Crous, D. litchicola R.G. Shivas, Grice \& Y.P. Tan, D. pseudomangiferae R.R. Gomes, Glienke \& Crous, D. pseudophoenicicola, and D. pterocarpicola Udayanga, X.Z. Liu \& K.D. Hyde (Fig. 2) and is phylogenetically distinct from the above-mentioned species with $100 \%$ bootstrap value. Phylogenetically, $D$. pseudomangiferae is the closest species to D. pescicola, differing by 58 nucleotides in concatenated alignment, in which 5 were distinct in the ITS region,

19 in the EF1- $\alpha$ region, 19 in the BT region and 15 in the CAL region.

\section{Pathogenicity testing}

All healthy peach shoots inoculated with Diaporthe species displayed disease symptoms 18 days after inoculation. All species caused brownish lesions on the outer epidermis and inner bark of the peach twigs. Mean lesion lengths varied significantly between the species (Fig. 4). Diaporthe eres isolates collected in this study clustered in three distinct clades in the phylogenetic analysis (Fig. 2). Diaporthe eres (3), which clustered in the Diaporthe cf. nobilis/Phomopsis fukushii complex (Fig. 2), caused the largest necrotic lesions $(74 \mathrm{~mm})$ of all the strains tested. It often girdled the twig, causing canker symptoms. Several erumpent pycnidia of $D$. eres (3) were observed around the necrosis. The necrotic lesions caused by $D$. eres (2) were depressed and affected the inner bark, but the lesion length $(33 \mathrm{~mm})$ was shorter than that caused by $D$. eres (3). Diaporthe eres (1) caused necrotic lesions similar in length to those of D. momicola (26 mm) (Fig. 4). However, the average lesion length of both D. eres (1) and D. momicola was significantly shorter than that caused by D. eres (3) or D. eres (2). Diaporthe pescicola and D. taoicola caused small necrotic lesions confined to the inoculation point $(24 \mathrm{~mm})$ and did not differ significantly from each other. No disease symptoms were detected on the control shoots. All pathogens were successfully re-isolated from symptomatic tissues (outer epidermis and inner bark) of all inoculated shoots, thus fulfilling Koch's postulates.

\section{Discussion}

This is the first study on Diaporthe species associated with diseased peach trees (P. persica) in China and is supported by data based on morphological characterizations, pathogenicity and phylogenetic analysis of combined ITS, EF1- $\alpha$, BT and CAL sequence data. Twelve representative isolates from P. persica were identified as $D$. eres. Two main clades in the phylogenetic analysis comprised isolates of three previously unidentified species, which are described herein as D. momicola, D. pescicola and D. taoicola. Diaporthe eres was the most aggressive species compared with other taxa isolated in this study.

Though nearly 130 Diaporthe species have been described worldwide, only 29 have been associated with Chinese hosts (Table 2). With the exception of D. eres, none of these species were identified in this study. Additional studies are needed on this subject to investigate this group of pathogens in different unexplored peach orchards in China.

Diaporthe eres, the type species of the genus, was described by Nitschke (1870) on Ulmus sp. collected in Germany. A comprehensive species concept was not developed for this species over the years. The lack of an ex-type culture for this generic type species was the main issue and Udayanga et al. (2014b) designated a well-characterized ex-epitype isolate (AR5193) from dead twigs of Ulmus laevis in Carpinion forest, Germany, and also defined the species limits of D. eres based on phylogenetic informative profiles. In their study, a combined alignment of 7 genes (ACT, Apn2, CAL, EF1- $\alpha$, HIS, FG1093 and BT) was incorporated, 
among which the EF1- $\alpha$, Apn2 and HIS genes were recognized as the best markers for defining species in the D. eres complex (Udayanga et al. 2014b). They omitted the ITS gene region from their phylogenetic analysis and stated that poorly supported non-monophyletic grouping was observed when ITS sequences were included in the combined analysis. This problem was also detected in our phylogenetic analyses, and and we observed two separate clades of the $D$. eres complex [D. eres (A) and D. eres (B), Fig. 2]. The D. eres (A) clade consisted the ex-epitype of D. eres (AR5193, Udayanga et al. 2014b), P. cotoneastri (CBS 439.82) and several other known taxa in the D. eres complex (Fig. 2). Diaporthe eres (1), which falls within the D. eres (A) clade, was found to be phylogenetically close to D. longicicola (Fig. 2) isolated from leaves of Lithocarpus glabra in Gutianshan Nature Reserve, Zhejiang Province, China, as described by Gao et al. (2015). The D. eres (B) clade (Fig. 2) was previously known as the Diaporthe cf. nobilis/Phomopsis fukushii complex (Gomes et al. 2013). Many of the isolates in the D. nobilis complex clustered within the D. eres clade of Udayanga et al. (2014b) based on the combined alignment of 7 genes (ACT, Apn2, CAL, EF1- $\alpha$, HIS, FG1093 and BT) and the application of GCPSR (Genealogical Concordance Phylogenetic Species Recognition).

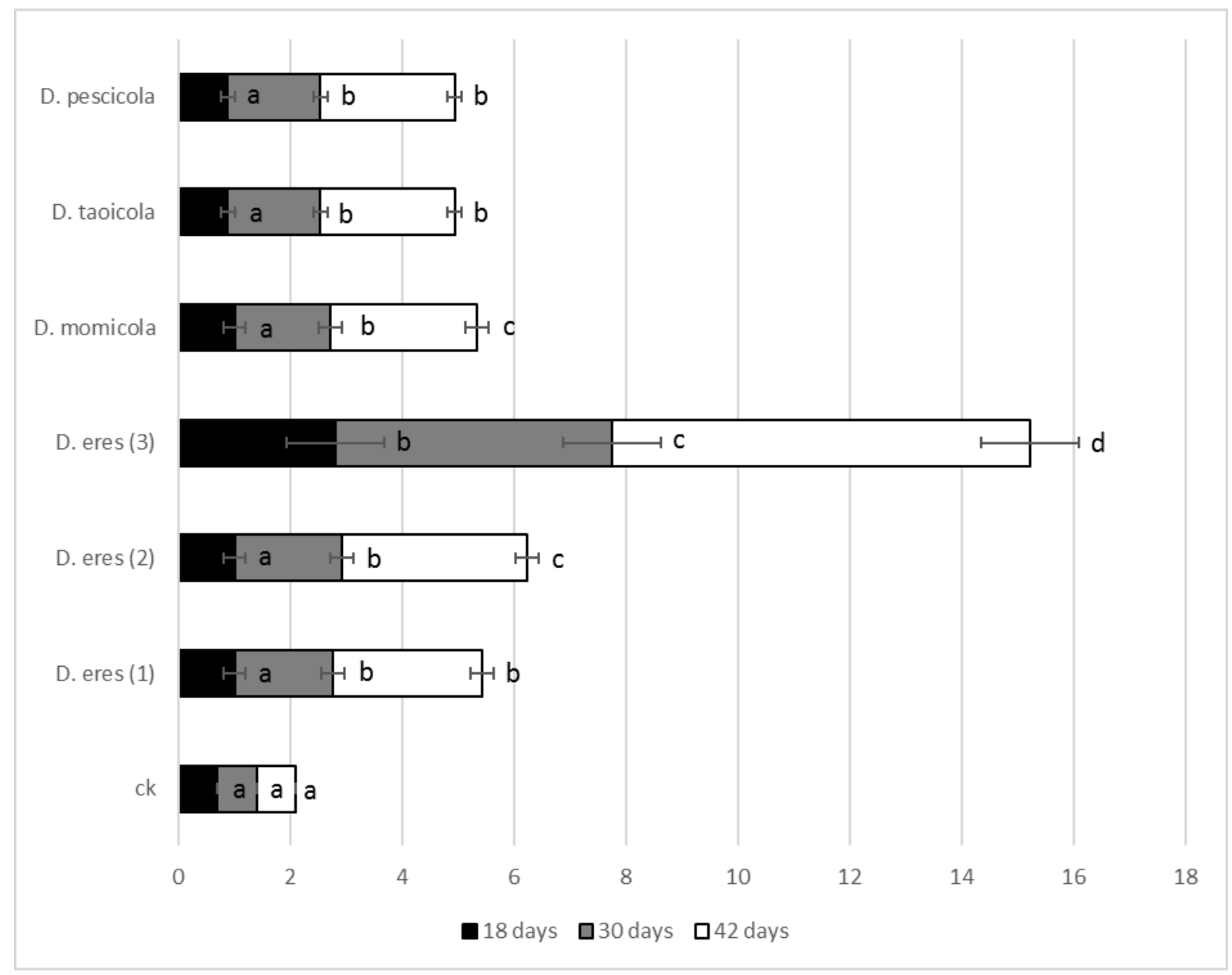

Figure 4 - Mean lesion length $(\mathrm{cm})$ caused by Diaporthe species associated with peach trunk disease in Hubei, China after 18, 30 and 42 days after inoculation with mycelium colonized agar plugs onto wounded detached healthy peach shoots $(\mathrm{n}=12)$. ck, non-inoculated control. Error bars indicate standard deviation of the mean. Significant differences $(P<0.05)$ between means are indicated with different letters according to Duncan's multiple range test.

Diaporthe eres was the most frequent species, comprising $69 \%$ of the isolates obtained in our study, and was the most aggressive species compared with other taxa upon inoculation of healthy peach shoots. Diaporthe eres has been reported as a weak to moderate pathogen of woody plants (Bai et al. 2015, Cinelli et al. 2016, Dissanayake et al. 2015, Gao et al. 2016, Huang et al. 2015, Lawrence et al. 2015, Petrovic et al. 2015, Udayanga et al. 2014b). Several studies proved that this species is a weak pathogen or opportunistic saprobe of grapevine in different geographic regions (Baumgartner et al. 2013, Dissanayake et al. 2015, 
Table 2 Diaporthe species isolated from various hosts in China.

\begin{tabular}{|c|c|c|c|c|}
\hline Species & Authority & Host & Locality (Province) & Reference \\
\hline D. amygdali & Udayanga, Crous \& K.D. Hyde & $\begin{array}{l}\text { Pyrus pyrifolia } \\
\text { Camellia } \mathrm{sp.}\end{array}$ & $\begin{array}{l}\text { Jiangxi, Yunnan } \\
\text { Sichuan }\end{array}$ & $\begin{array}{l}\text { Bai et al. } 2015 \\
\text { Gao et al. } 2016\end{array}$ \\
\hline D. apiculata & Y.H. Gao \& L. Cai & Camellia sp. & Jiangxi, Guangxi & Gao et al. 2016 \\
\hline D. aquatica & D.M. Hu, L. Cai \& K.D. Hyde & aquatic habitats & Guizhou & Hu et al. 2012 \\
\hline D. arecae & H.C. Srivast., Zakia \& Govindar & Citrus sinensis & Fujian, Jiangxi, Yunnan, Zhejiang & Huang et al. 2015 \\
\hline D. biconispora & F. Huang, K.D. Hyde \& H.Y. Li & Citrus sinensis & Jiangxi, Guangxi, Fujian & Huang et al. 2015 \\
\hline D. biguttulata & F. Huang, K.D. Hyde \& H.Y. Li & Citrus limon & Yunnan & Huang et al. 2015 \\
\hline D. citri & F.A. Wolf & Citrus sp. & Zhejiang, Huangyan, Jiangxi & Huang et al. 2013, 2015 \\
\hline D. citriasiana & F. Huang, K.D. Hyde \& H.Y. Li & Citrus sp. & Shaanxi, Jiangxi, Zhejiang & Huang et al. 2013, 2015 \\
\hline D. citrichinensis & F. Huang, K.D. Hyde \& H.Y. Li & Citrus sp. & Shaanxi, Guangxi, Fujian & Huang et al. 2013, 2015 \\
\hline D. compacta & Y.H. Gao \& L. Cai & Camellia sp. & Jiangxi & Gao et al. 2016 \\
\hline D. discoidispora & F. Huang, K.D. Hyde \& H.Y. Li & Citrus sp. & Jiangxi & Huang et al. 2015 \\
\hline D. endophytica & R.R. Gomes, C. Glienke \& Crous & Citrus sp. & Fujian & Huang et al. 2015 \\
\hline \multirow[t]{5}{*}{ D. eres } & Nitschke & Aralia elata & northeastern China & Bai et al. 2015 \\
\hline & & Citrus sp. & Guangxi, Jiangxi, Zhejiang & Huang et al. 2015 \\
\hline & & Vitis vinifera & Beijing, Zhejiang & Dissanayake et al. 2015 \\
\hline & & Pyrus pyrifolia & Jiangxi & Wu et al. 2012 \\
\hline & & Camellia sp. & Sichuan & Gao et al. 2016 \\
\hline \multirow[t]{2}{*}{ D. hongkongensis } & R.R. Gomes, C. Glienke \& Crous & $\begin{array}{l}\text { Citrus sp., } \\
\text { Vitis vinifera }\end{array}$ & $\begin{array}{l}\text { Zhejiang, Guangxi } \\
\text { Beijing }\end{array}$ & $\begin{array}{l}\text { Huang et al. } 2015 \\
\text { Dissanayake et al. } 2015\end{array}$ \\
\hline & & Camellia sp. & Guangxi & Gao et al. 2016 \\
\hline D. lithocarpus & Y.H. Gao, W. Sun \& L. Cai & Lithocarpus sp. & Zhejiang & Gao et al. 2014 \\
\hline D. longicolla & (Hobbs) J.M. Santos, Vrandečić \& A.J.L. Phillips & Pyrus pyrifolia & Jiangxi, Fujian, Hubei & Bai et al. 2015 \\
\hline D. mahothocarpus & Y.H. Gao, W. Sun \& L. Cai & Lithocarpus sp. & Zhejiang & Gao et al. 2014 \\
\hline D. multigutullata & F. Huang, K.D. Hyde \& H.Y. Li & Citrus sp. & Fujian & Huang et al. 2015 \\
\hline D. neotheicola & A.J.L. Phillips \& J.M. Santos & Pyrus bretschneideri & Yunnan, Jiangxi, Fujian & Bai et al. 2015 \\
\hline D. oraccinii & Y.H. Gao \& L. Cai & Camellia sp. & Jiangxi & Gao et al. 2016 \\
\hline D. ovalispora & F. Huang, K.D. Hyde \& H.Y. Li & Citrus sp. & Yunnan & Huang et al. 2015 \\
\hline D. pentriteum & Y.H. Gao \& L. Cai & Camellia sp. & Jiangxi & Gao et al. 2016 \\
\hline D. phaseolorum & (Cooke \& Ellis) Sacc. & Vitis vinifera & Beijing & Dissanayake et al. 2015 \\
\hline
\end{tabular}


Table 2 Continued.

\begin{tabular}{|c|c|c|c|c|}
\hline D. phragmitis & Crous & Phragmitis australis & Beijing & Crous et al. 2014 \\
\hline D. rostrata & C.M. Tian, X.L. Fan \& K.D. Hyde & Juglans mandshurica & Gansu & Fan et al. 2015 \\
\hline \multirow[t]{2}{*}{ D. sojae } & Lehman & Vitis vinifera & Beijing & Dissanayake et al. 2015 \\
\hline & & Citrus sp. & Shaanxi & Huang et al. 2015 \\
\hline D. subclavata & F. Huang, K.D. Hyde \& H.Y. Li & Citrus sp. & Fujian, Guangdong & Huang et al. 2015 \\
\hline D. ternstroemia & Y.H. Gao, W. Sun \& L. Cai & Ternstroemia sp. & Zhejiang & Gao et al. 2014 \\
\hline D. unshiuensis & F. Huang, K.D. Hyde \& H.Y. Li & Citrus sp. & Guangxi & Huang et al. 2015 \\
\hline
\end{tabular}

Kaliterna et al. 2012). Regarding the pathogenicity of D. eres, we observed a variation in the aggressiveness of our isolates in the $D$. eres species complex. Isolates of D. eres (3), which resides in the D. eres (B) clade (former D. nobilis/P. fukushii complex in Gomes et al. 2013), were the most aggressive. The two other $D$. eres isolates [D. eres (1) and D. eres (2), Fig. 2], which belong to the D. eres (A) clade, were less aggressive, indicating that this species complex has wide variability with respect to aggressiveness. Diaporthe eres (3) produced significantly longer $(\mathrm{p}<0.1)$ lesions compared with the other Diaporthe isolates. In contrast, Thomidis \& Michailides (2009) showed that all three tested D. eres isolates in their study were equally aggressive when tested on peach shoots in the field. The newly described D. momicola, D. pescicola and D. taoicola were the least frequent species isolated $(12.5 \%, 10 \%, 8.5 \%$, respectively). With respect to pathogenicity, when inoculated into detached peach shoots, these newly described species showed no difference in disease symptoms and were statistically equal in terms of severity. During our study period, all isolates of Diaporthe caused gum exudation of inoculated peach shoots.

The present study aimed to reveal the diversity of Diaporthe species in diseased P. persica trees in Jinshui Experimental Orchard in Hubei Academy of Agriculture Sciences in Hubei Province, through a combined morphological and molecular phylogenetic approach. The phylogenies inferred from combined multi-locus sequences grouped isolates from $P$. persica that corresponded to previously described species, i.e., D. eres, and three novel species that are described in this paper. Since the disease symptoms of peach trees caused by Diaporthe species are similar to those caused by Botryosphaeriaceae species (Wang et al. 2011), peach tree diseases caused by Diaporthe could be confused with symptoms caused by Botryosphaeriaceae species in disease surveys. Future studies should broaden the sampling range to include more specimens from different locations in China to study their intraspecific relationships and population genetics.

\section{Conclusions}

This is the first detailed report of Diaporthe species isolated from diseased peach trees in Chinese peach orchards. The association of $D$. eres with three additional new species in symptomatic peach was revealed for the first time. Diaporthe eres was the dominant species, and it also proved to be the most aggressive in inoculations conducted on excised peach shoots.

\section{Acknowledgments}

This work was financed by JNKYT201605, Innovation funds of IPEP, BAAFS and CARS-30. 


\section{References}

Adaskaveg JE, Ogawa JM. 1990 - Wood decay pathology of fruit and nut trees in California. Plant disease 74, 341-352.

Adaskaveg JE, Miller RW, Gilbertson RL. 1993 - Wood decay, lignicolous fungi, and decline of peach trees in South Carolina. Plant disease 77, 707-711.

Bai Q, Zhai LF, Chen XR, Hong N et al. 2015 - Biological and molecular characterization of five Phomopsis species associated with pear shoot canker in China. Plant disease 99, 1704-1712.

Baumgartner K, Fujiyoshi PT, Travadon R, Castlebury LA et al. 2013 - Characterization of species of Diaporthe from wood cankers of grape in eastern North American vineyards. Plant disease 97, 912 920.

Carbone, I, Kohn LM. 1999 - A method for designing primer sets for speciation studies in filamentous ascomycetes. Mycologia 99, 553-556.

Chen C, Bock CH, Hotchkiss MH, Garbelotto MM, Cottrell TE. 2015 - Observation and identification of wood decay fungi from the heartwood of peach tree limbs in central Georgia, USA. European Journal of Plant Pathology 143, 11-23.

Cinelli T, Mondello V, Marchi G, Burruano S et al. 2016 - First report of Diaporthe eres associated with cane blight of grapevine (Vitis vinifera) in Italy. Plant disease 100, 532-532.

Crous PW, Wingfield MJ, Schumacher RK, Summerell BA et al. 2014 - Fungal Planet description sheets, 281-319. Persoonia 33, 212-292.

Diogo ELF, Santos JM, Phillips AJL. 2010 - Phylogeny, morphology and pathogenicity of Diaporthe and Phomopsis species on almond in Portugal. Fungal Diversity 44, 107-115.

Dissanayake AJ, Liu M, Zhang W, Chen Z et al. 2015 - Morphological and molecular characterization of Diaporthe species associated with grapevine trunk disease in China. Fungal Biology 119, 283-284.

Doepel RF, McLean GD, Goss OM. 1979 - Canning peach decline in Western Australia. I. Association between trunk cankers, trunk pruning wounds and crotch angles of acaffold limbs. Australian Journal of Agricultural Research 30, 1089-1100.

Eguchi N, Hara H. 2005 - Influence of preservation temperature on rot extent of fruit core rot of Japanese pear caused by Phomopsis spp. Annual report of the Kanto-Tosan plant protection society 52, 51-52.

Fan XL, Hyde KD, Udayanga D, Wu XY, Tian CM. 2015 - Diaporthe rostrata, a novel ascomycete from Juglans mandshurica associated with walnut dieback. Mycological progress 14, 82-90.

Farr DF, Castlebury LA, Pardo-Schultheiss RA. 1999 - Phomopsis amygdale causes peach shoot blight of cultivated peach trees in the southeastern United States. Mycologia 91, 1008-1015.

Faust M, Timon BL. 2010 - Origin and dissemination of peach. Horticultural Reviews. 331 pages. doi,10.1002/9780470650585.ch10. ISBN 978-0-470-65058-5.

Gao YH, Sun W, Su YY, Cai L. 2014 - Three new species of Phomopsis in Gutianshan Nature Reserve in China. Mycological Progress 13, 111-121.

Gao YH, Su YY, Sun W, Cai L. 2015 - Diaporthe species occurring on Lithocarpus glabra in China, with descriptions of five new species. Fungal Biology 119, 295-309.

Gao YH, Liu F, Cai L. 2016 - Unravelling Diaporthe species associated with Camellia. Systematics and Biodiversity 14, 102-117.

Geissler C. 2009 - The New Oxford Book of Food Plants. Oxford, Oxford University Press.

Glass NL, Donaldson GC. 1995 - Development of primer sets designed for use with the PCR to amplify conserved genes from filamentous Ascomycetes. Applied Environment Microbiology 61, 1323-1330.

Gomes RR, Glienke C, Videira SIR, Lombard L et al. 2013 - Diaporthe, a genus of endophytic, saprobic and plant pathogenic fungi. Persoonia 31, 1-41.

Hall T. 2006 - Bioedit 7.5.0.3. Department of Microbiology, North Carolina State University. http, //www.mbio.ncsu.edu/BioEdit/Bioedit.html.

Hu DM, Cai L, Hyde KD. 2012 - Three new ascomycetes from freshwater in China. Mycologia 104, 14781489.

Huang F, Hou X, Dewdney MM, Fu Y et al. 2013 - Diaporthe species occurring on citrus in China. Fungal Diversity 61, 237-250.

Huang F, Udayanga D, Wang XH, Hou X et al. 2015 - Endophytic Diaporthe associated with Citrus, A phylogenetic reassessment with seven new species from China. Fungal Biology119, 331-347.

Index Fungorum 2016. http, //www.indexfungorum.org/names/names.asp Accessed 25 January 2017.

Jayasiri SC, Hyde KD, Abd-Elsalam KA, Abdel-Wahab MA et al. 2015 - The faces of fungi database, fungal names linked with morphology, molecular and human attributes. Fungal Diversity 74, 3-18. 
Kaliterna J, Milicevici T, Cvjetkovic B. 2012 - Grapevine trunk diseases associated with fungi from the Diaporthaceae family in Croatian vineyards. Arch Ind Hyg Toxicol 63, 471-478.

Katoh K, Toh H. 2010 - Recent developments in the MAFFT multiple sequence alignment program. Briefings in Bioinformatics 9, 286-298.

Lalancette N. 1999 - Fusicoccum canker of peach disease incidence and yield loss. Pa. Fruit News 79, 4445.

Lalancette N, Robison DM. 2001 - Seasonal availability of inoculum for constriction canker of peach in New Jersey. Phytopathology 91, 1109-1115.

Lalancette N, Foster KA, Robison DM. 2003 - Quantitative models for describing temperature and moisture effects on sporulation of Phomopsis amygdali on peach. Phytopathology 93, 1165- 1172.

Latham AJ, Morgan-Jones G, Campbell HL. 1992 - Phomopsis dieback of peach shoots in Alabama. Plant disease 76, 426.

Lawrence DP, Travadon R, Baumgartner K. 2015 - Diversity of Diaporthe species associated with wood cankers of fruit and nut crops in northern California. Mycologia 107, 926-940.

Maharachchikumbura SSN, Hyde KD, Jones EBG, McKenzie EHC et al. 2015 - Towards a natural classification and backbone tree for Sordariomycetes. Fungal Diversity 72, 199-301.

Nylander JAA. 2004 - MrModeltest v2. Program distributed by the author. Evolutionary Biology Centre, Uppsala University, Sweden.

Page RD. 1996 - TreeView, an application to display phylogenetic trees on personal computers. Computer Applications in the Biosciences 12, 357-358.

Petersen DH. 1960 - Hymenomycetous fungi except polyporus associated with wood decay of living peach trees in South Carolina. Plant Disease Report 44, 891-893.

Petersen DH. 1961 - Polyporus spp. Associated with wood decay of living peach trees in South Carolina. Plant Disease Report 45, 186-189.

Petrovic K, Vidic M, Riccioni L, Dordevic V, Rajkovic D. 2015 - First Report of Diaporthe eres Species Complex Causing Seed Decay of Soybean in Serbia. Plant disease 99, 1186-1186.

Rayner RW. 1970 - A mycological colour chart. Commonwealth Mycological Institute, Kew, UK.

Ronquist F, Huelsenbeck JP. 2003 - MrBayes 3, Bayesian phylogenetic inference under mixed models. Bioinformatics 19, 1572-1574.

Rossman AY, Crous PW, Hyde KD, Hawksworth DL et al. IMA fungus 6, 507-523.

Sikora EJ. 2004 - Fungal gummosis of peach. Alabama A \& M and Auburn Universities, Plant Disease Notes. ANR-1183.

Singh A, Patel RK, Babu KD, and De, LC. 2007 - Low chiling peaches. Underutilized and underexploited horticultural crops. New Delhi, New India Publishing. p. 90.ISBN 978-8189422-69-1.

Swofford DL. 2003 - PAUP*, phylogenetic analysis using parsimony (*and other methods), version 4. Sinauer Associates, Sunderland, Massachusetts.

Thomidis T, Michailides TJ. 2009 - Studies on Diaporthe eres as a new pathogen of peach trees in Greece. Plant Disease 93, 1293-1297.

Udayanga D, Liu XZ, Crous PW, McKenzie EHC et al. 2012 - A multi-locus phylogenetic evaluation of Diaporthe (Phomopsis) Fungal Diversity 56, 157-171.

Udayanga D, Castlebury LA, Rossman AY, Chukeatirote E, Hyde KD. 2014b - Insights into the genus Diaporthe, phylogenetic species delimitation in the D. eres species complex. Fungal Diversity 67, 203-229.

Uddin W, Stevenson KL, Pardo-Schultheiss RA. 1997 - Pathogenicity of a species of Phomopsis causing a shoot blight on peach in Georgia and evaluation of possible infection courts. Plant Disease 81, 983989.

Uddin W, Stevenson KL, Pardo-Schultheiss RA, Rehner SA. 1998 - Pathogenic and molecular characterization of three Phomopsis isolates from peach, plum, and Asian pear. Plant Disease 82, 732-737.

Voronin EI, Kartausova VA. 1990 - Phomopsis blight of peach in the Crimea. Nauchno-Tekhnicheskii Byulleten' Vsesoyuznogo Ordena Lenina i Ordena Druzhby Narodov Nauchno-Issledovatel'skogo Instituta Rastenievodstva imeni N. I. Vavilova 205, 52-53.

Wang F, Zhao L, Li G, Huang J, Hsiang T. 2011 - Identification and characterization of Botryosphaeria spp. causing gummosis of peach trees in Hubei Province, central China. Plant Disease 95, 1378-1384.

White TJ, Bruns T, Lee J, Taylor J. 1990 - Amplification and direct sequencing of fungal ribosomal RNA genes for phylogenetics. In, Innis MA, Gelfand DH, Sninsky JJ, White TJ (eds), PCR protocols, a guide to methods and applications, 315-322. Academic Press, San Diego, California, USA. 
Wu H, Yang HY, You XL, Li YH. 2012 - Isolation and characterization of saponin-producing fungal endophytes from Aralia elata in northeast China. International journal of molecular sciences 13, $16255-16266$. 